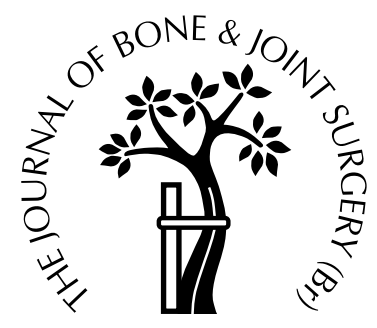

\title{
Changes in the expression of Fas, osteonectin and osteocalcin with age in the rabbit growth plate
}

\author{
Toshimi Aizawa, Helmtrud I. Roach, Shoichi Kokubun, \\ Yasuhisa Tanaka \\ From Tohoku University School of Medicine, Sendai, Japan
}

C hondrocytes of the growth plate are generally assumed to undergo apoptosis, but the mechanisms which induce this cell death are not known. The Fas receptor is a mediator of the apoptotic signal in some systems. We studied its expression in situ in growth plates of rabbits aged from five to 20 weeks. In addition, we investigated the immunolocalisation in the growth plates of the bone proteins, osteonectin and osteocalcin, and the changes in their expression with age.

The Fas-positive chondrocytes were found mostly in the hypertrophic zone, as were the osteonectin-positive and osteocalcin-positive cells. The percentage of Fas-positive cells increased with age whereas little change was found in the number of osteonectinpositive and osteocalcin-positive chondrocytes.

Many of the Fas-positive chondrocytes were also TUNEL-positive. This strongly suggests that apoptosis in the growth plate is mediated through the Fas system.

Double immunostaining for osteocalcin and Fas showed that not all hypertrophic chondrocytes were of the same cell type. Some chondrocytes stained for osteocalcin only, others for Fas only, while some were positive for both.

J Bone Joint Surg [Br] 1998;80-B:880-7.

Received 6 October 1997; Accepted after revision 26 February 1998

Longitudinal growth of the long bones takes place at the growth plate in which resting chondrocytes at the top of the plate are stimulated to proliferate, then proceed through several maturational stages, to hypertrophy at the bottom of the plate. The morphological appearance of hypertrophic

T. Aizawa, MD, University Lecturer

S. Kokubun, $\mathrm{MD}, \mathrm{PhD}$, Professor and Chairman

Y. Tanaka, MD, PhD, University Lecturer

Department of Orthopaedic Surgery, Tohoku University School of Medicine, 1-1 Seiryo-machi, Aoba-ku, Sendai 980-8574, Japan.

H. I. Roach, $\mathrm{PhD}$, Lecturer

Department of Orthopaedics, Southampton General Hospital, Tremona Road, Shirley, Southampton SO16 6YD, UK.

Correspondence should be sent to $\mathrm{Dr} \mathrm{T}$. Aizawa.

(C)1998 British Editorial Society of Bone and Joint Surgery 0301-620X/98/58430\$2.00 chondrocytes indicates that the terminal chondrocytes undergo programmed cell death. ${ }^{1,2}$ End-labelling studies have identified cells with fragmented DNA in the hypertrophic zone suggesting that the chondrocytes die through the process of apoptosis. ${ }^{3-6}$ The Fas receptor protein, ${ }^{7}$ also termed APO-1 or CD95, which belongs to the tumour necrosis factor (TNF) family, is one of the cell-surface proteins which mediate apoptosis ${ }^{8,9}$ and can be detected by immunostaining methods. ${ }^{10,11}$ The Fas receptor is expressed in many tissues, including the thymus, liver, heart, lung and ovary, ${ }^{12}$ but there have been no reports of its expression in the chondrocytes of the growth plate.

Osteonectin and osteocalcin are typical non-collagenous bone proteins produced by osteoblasts. ${ }^{13,14}$ Their function in bone may be related to the process of mineralisation and/ or resorption. ${ }^{15}$ Osteonectin has a wide tissue distribution, but osteocalcin is generally considered to be a specific marker of osteoblasts. ${ }^{16}$ In previous studies of the mammalian growth plate in vivo, osteocalcin has not been demonstrated in the chondrocytes or in the cartilage matrix. ${ }^{14,17,18}$ It has been localised in the hypertrophic chondrocytes of the chick growth plate and in fracture callus in the rabbit and rat. ${ }^{19-22}$ Osteocalcin expression in the mammalian growth plate in vivo has not been reported nor have changes in the expression of osteocalcin and osteonectin with increasing age.

We now have in situ techniques which can examine whether chondrocytes undergo apoptosis. New monoclonal antibodies to Fas as well as to osteonectin and osteocalcin are available. Using single and combined immunocytochemical techniques, we studied the growth plates in rabbits aged between five and 20 weeks. We investigated whether chondrocyte death in the growth plate was mediated through the Fas system and the relationship of the number of Fas-positive cells to chondrocytes containing DNA-strand breaks which we have previously reported. ${ }^{23}$ We also examined osteocalcin expression in the mammalian growth plate in vivo and the changes which occur in the expression of osteonectin and osteocalcin with age.

\section{Materials and Methods}

We used 16 Japanese white rabbits divided into four equal groups which were killed by intravenous injection of pento- 
barbital sodium at each of 5, 10, 15 and 20 weeks. In the rabbit, the growth plate of the long bones closes between 20 and 30 weeks. The epiphyseal growth plate with metaphyseal and epiphyseal bones was obtained from the femoral head of each rabbit.

Coronal sections $5 \mathrm{~mm}$ thick were fixed in $10 \%$ formalin for three days, decalcified by EDTA at $4^{\circ} \mathrm{C}$ for ten days, embedded in paraffin and cut into slices $2.5 \mu \mathrm{m}$ thick.

Sections were either stained with haematoxylin and eosin (HE) or immunostained with monoclonal antibodies for Fas, osteonectin and osteocalcin using the labelled streptavidin biotin (LSAB) method. The sections stained with $\mathrm{HE}$ allowed study of the morphological and structural differences in the growth plates with age (Fig. 1). The height of the growth plates was measured microscopically at the central portion of each femoral head using the HE sections.

The antibody to recombinant Fas receptor protein, clone ZB-4, was purchased from Medical and Biological Laboratories Ltd, Nagoya, Japan ${ }^{10}$ and those to osteonectin and osteocalcin from Takara Shuzo Co Ltd, Kyoto, Japan. The

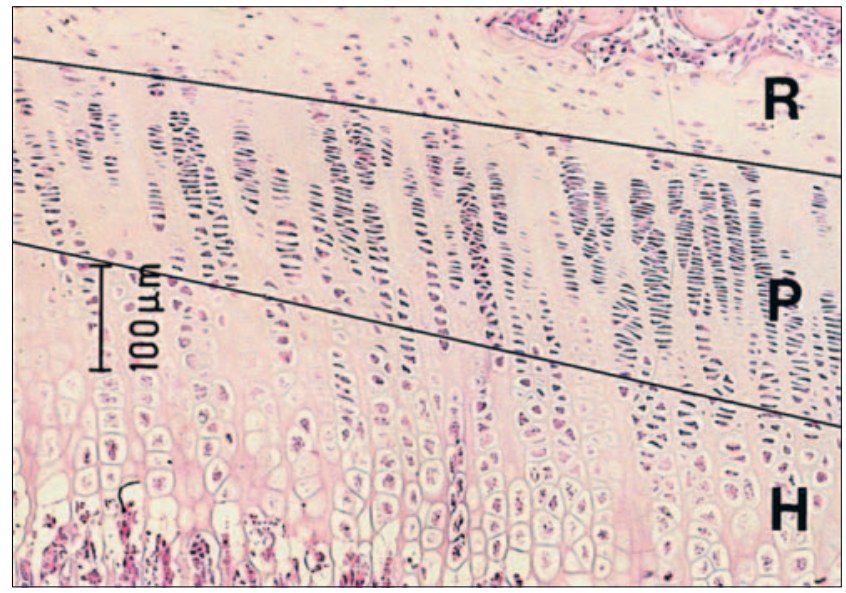

Fig. 1a

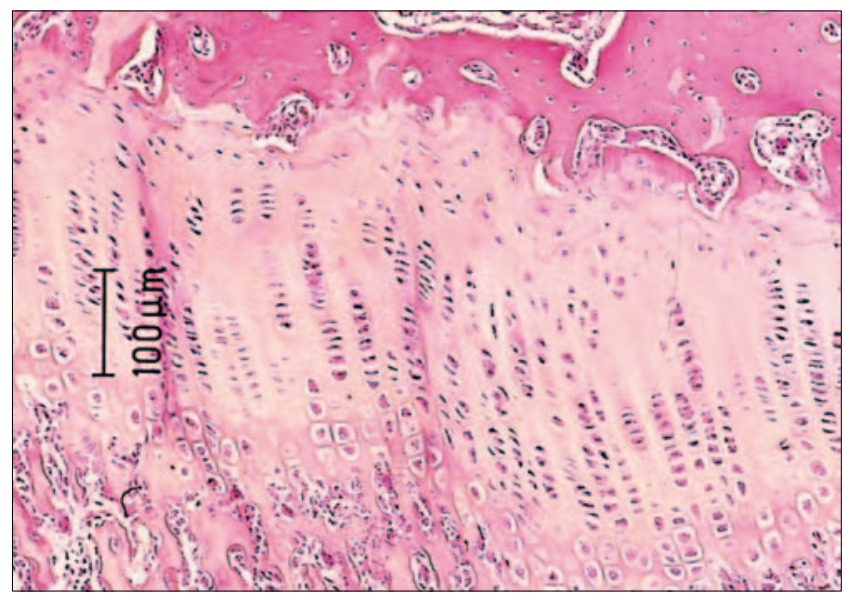

Fig. 1c osteonectin antibody belongs to the subclass $\operatorname{IgG}_{1}$ and reacts with bone and platelet osteonectin while that to osteocalcin is of the subclass $\operatorname{IgG}_{2 \mathrm{a}}$ and binds to an epitope around the $17 \gamma$-carboxyglutamic acid position near the $\mathrm{N}$ terminal region. ${ }^{24}$ The dilution of Fas was 1:50, of osteonectin 1:100 and of osteocalcin 1:10. In all three immunostainings, the reaction time was 60 minutes at room temperature. 3,3'-Diaminobenzidine tetrahydrochloride (DAB) was used as a substrate counterstained with methyl green. Control sections were incubated with mouse serum and no staining was found.

Quantification of Fas, osteonectin and osteocalcin expression. For each antibody and each rabbit block, we performed immunocytochemistry on several sections until at least two showed the same immunostaining pattern. Then according to the calculation method of Ueda et $\mathrm{al}^{25}$ for obtaining the positive ratio of the $\mathrm{Ki}-67$ index, five fields containing the largest number of positive cells with wellstained cytoplasm were selected from one of these sections and the positively and negatively stained cells counted three times in each selected region at a magnification

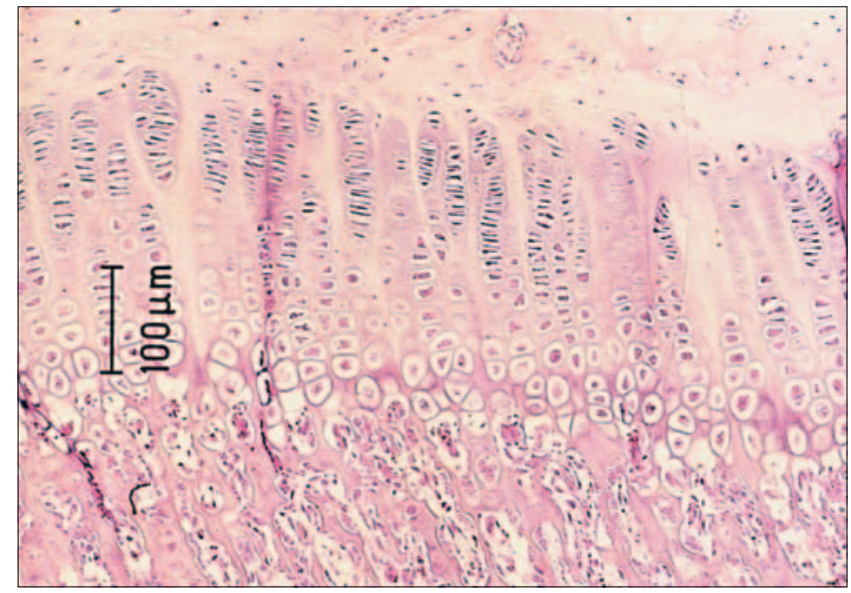

Fig. 1b

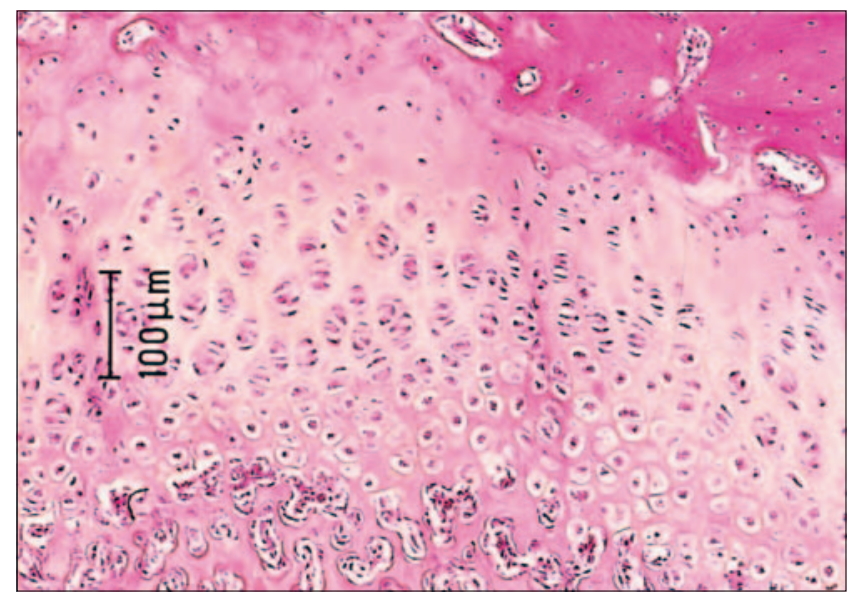

Fig. 1d

The growth plate of the femoral head from a) 5-week, b) 10-week, c) 15-week and d) 20-week-old rabbits (R, resting zone; P, proliferating zone; H, hypertrophic zone; haematoxylin and eosin $\times 120$ ) 
Table I. Mean ( \pm SD) percentage of Fas-, osteonectin- and osteocalcin-positive chondrocytes in rabbit growth plates at $5,10,15$ and 20 weeks of age

\begin{tabular}{lcccc}
\hline & Weeks & & \\
\cline { 2 - 5 } & $\mathbf{5}$ & $\mathbf{1 0}$ & $\mathbf{1 5}$ & $\mathbf{2 0}$ \\
\hline Fas-positive cells & $21.4 \pm 5.5$ & $26.3 \pm 8.5$ & $52.6 \pm 8.0$ & $42.0 \pm 6.0$ \\
Total cells & $593.5 \pm 236.7$ & $450.9 \pm 141.3$ & $323.3 \pm 118.6$ & $218.5 \pm 35.0$ \\
Fas-positive cells (\%) & $4.4 \pm 2.7^{\mathrm{a}, \mathrm{b}}$ & $6.4 \pm 3.4^{\mathrm{c}}$ & $17.6 \pm 5.0^{\mathrm{a}}$ & $19.9 \pm 5.2^{\mathrm{b}, \mathrm{c}}$ \\
Osteonectin-positive cells & $56.4 \pm 15.3$ & $45.1 \pm 8.3$ & $50.1 \pm 17.6$ & $50.5 \pm 11.4$ \\
Total cells & $682.3 \pm 108.4$ & $462.0 \pm 68.0$ & $341.1 \pm 76.4$ & $235.4 \pm 32.9$ \\
Osteonectin-positive cells (\%) & $8.7 \pm 4.1^{\mathrm{d}}$ & $9.9 \pm 2.0^{\mathrm{e}}$ & $14.4 \pm 2.6$ & $21.4 \pm 2.9^{\mathrm{d}, \mathrm{e}}$ \\
Osteocalcin-positive cells & $47.7 \pm 9.3$ & $38.5 \pm 6.7$ & $46.5 \pm 14.1$ & $34.6 \pm 10.6$ \\
Total cells & $642.6 \pm 71.6$ & $451.1 \pm 79.5$ & $334.1 \pm 101.1$ & $205.6 \pm 19.7$ \\
Osteocalcin-positive cells (\%) & $7.5 \pm 1.6^{\mathrm{f}, \mathrm{g}}$ & $8.6 \pm 1.1^{\mathrm{h}, \mathrm{i}}$ & $14.0 \pm 2.6^{\mathrm{f}, \mathrm{h}}$ & $16.6 \pm 3.5^{\mathrm{g}, \mathrm{i}}$ \\
\hline
\end{tabular}

a,b,c,d,e,f,g,h,i :p $<0.05$

$\times 200$, i.e., five regions were counted per rabbit and for each antibody. The mean number of positive chondrocytes was divided by the total number of cells in the region and the percentages of Fas-positive, osteonectin-positive and osteocalcin-positive cells were determined in the whole growth plate and the individual zones as in our previous study. ${ }^{23}$

Double immunostaining. Some sections were doublestained for both Fas and osteocalcin. The sections were incubated with the primary antibody for osteocalcin for four hours followed by the streptavidin-biotin method linked to peroxidase and 3-amino, 9-ethylcarbazole (AEC). This resulted in a brown reaction product. Incubation with the second primary antibody to Fas took place overnight. This was visualised using the alkaline-phosphatase antialkaline-phosphatase method (APAAP) with Fast Blue as a substrate resulting in a dark blue reaction product. ${ }^{26}$ Control sections were incubated with mouse serum (negative control) and only background staining was found.

We performed another combined staining for the Fas receptor and terminal deoxynucleotidyl transferase-mediated deoxyuridine triphosphate (dUTP)-biotin nick end labelling (TUNEL). Sections were stained for Fas as described above with detection of the antibody by peroxidase and AEC. This was followed by a modified TUNEL reaction in which no proteinase $\mathrm{K}$ digestion was carried out and the incorporation of dUTP-biotin was detected by binding of avidin-alkaline phosphatase with Fast Blue as a substrate. Negative controls were incubated without Fas in the first step and were not reacted by terminal transferase in the second. They were otherwise treated as above. No positive cells were found in the control.

Statistical analysis. We used Student's $t$-test and the means and standard deviations were calculated for each age group and three individual zones. A $p$ value of $<0.05$ was considered significant.

\section{Results}

In the five- and ten-week groups, the proliferating zone of the growth plate occupied about half its height (Figs 1a and 1b). ${ }^{27-29}$ With increasing age, the height of the growth plate became progressively less; in the 5-, 10-, 15- and 20-week age groups the mean heights were $600,415,358$ and $270 \mu \mathrm{m}$, respectively. The columnar structures from the proliferating to hypertrophic zones were maintained until 15 weeks but the widths of the resting and proliferating zones became narrower (Fig. 1c). In the growth plate of the 20-week group, there were major structural changes in that the columnar structure was disarranged in addition to narrowing of every zone. There were fewer resting and proliferating chondrocytes and in some areas they were hypertrophic. The 'spicules' of endochondral bone below the chondro-osseous junction were much thicker than those in the five-week growth plates and contained viable cells (Fig. 1d).

Chondrocytes stained positively for the Fas receptor in every age group and in all three zones. The overall percentage of Fas-positive cells, averaged over all three growth-plate zones, increased from $4.4 \%$ to $19.9 \%$ between five and 20 weeks (Table I). Most of the labelled cells, however, were in the hypertrophic zone with some staining in the resting zone, whereas the proliferating cells showed positive staining only occasionally (Fig. 2). In the hypertrophic zone, there was a considerable increase in the percentage of the Fas-positive cells between ten and 15

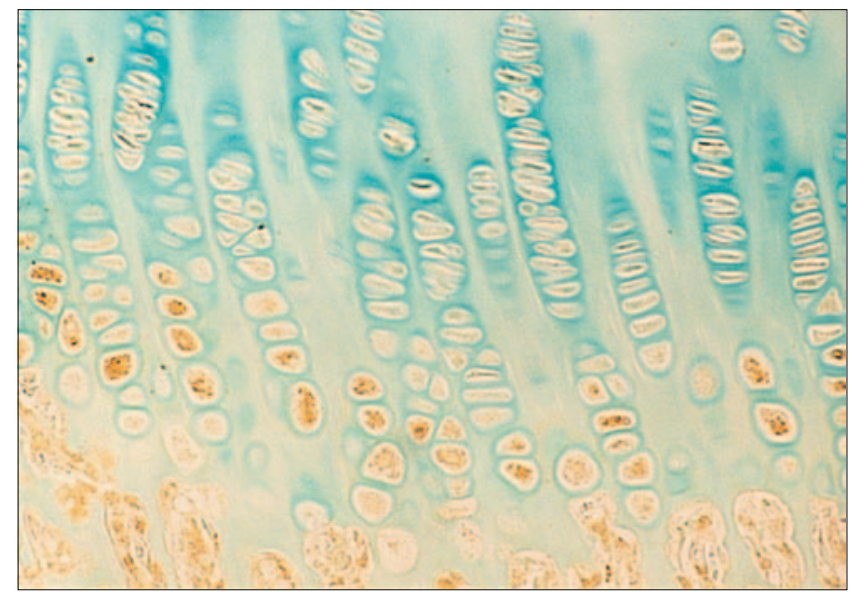

Fig. 2

Immunostaining for the Fas receptor protein in a 15-week-old rabbit growth plate. Chondrocytes with well-stained cytoplasm (brown) are mainly found in the hypertrophic zone. About half of the hypertrophic chondrocytes expressed this protein $(\times 160)$. 

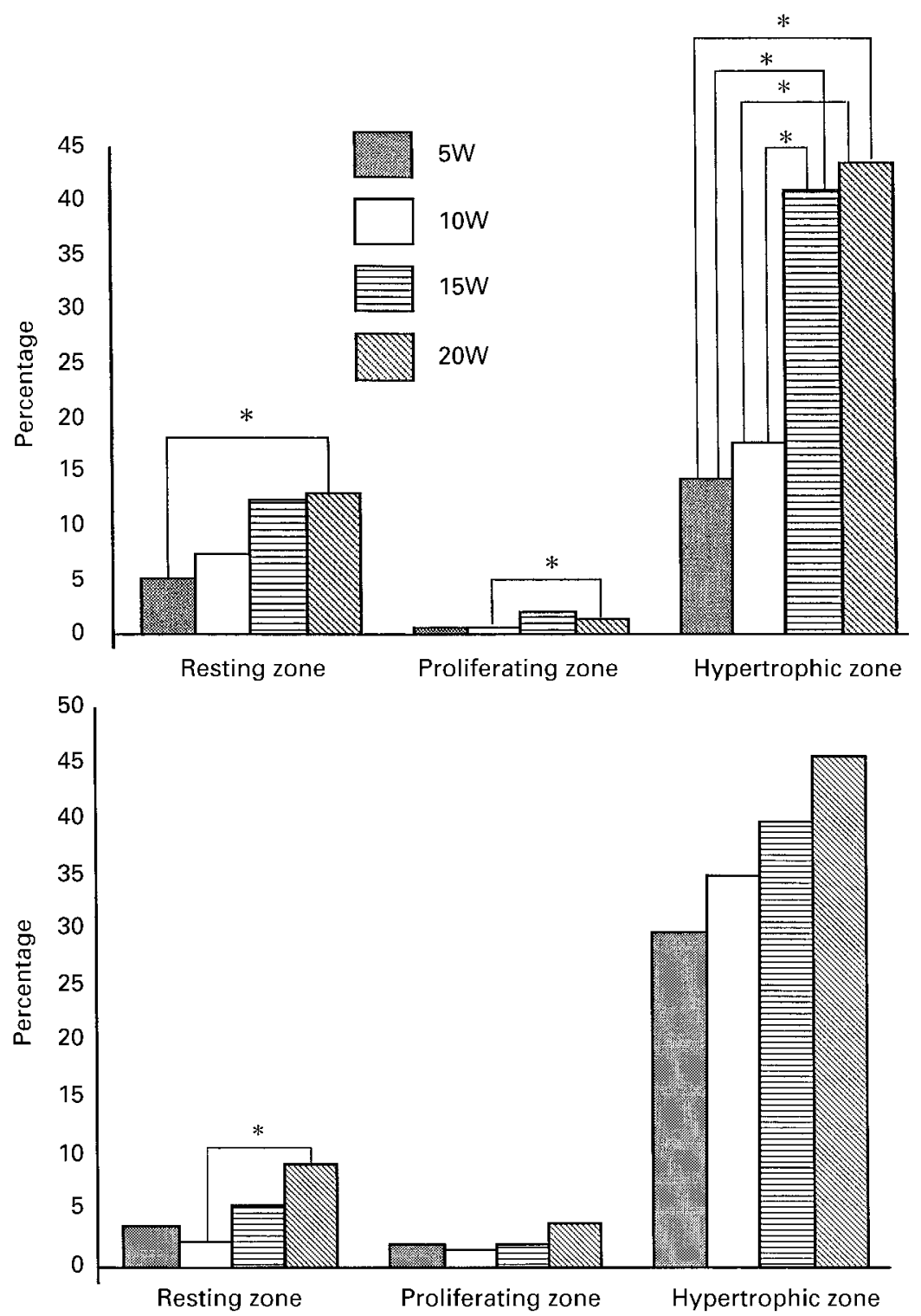

Fig. 3b

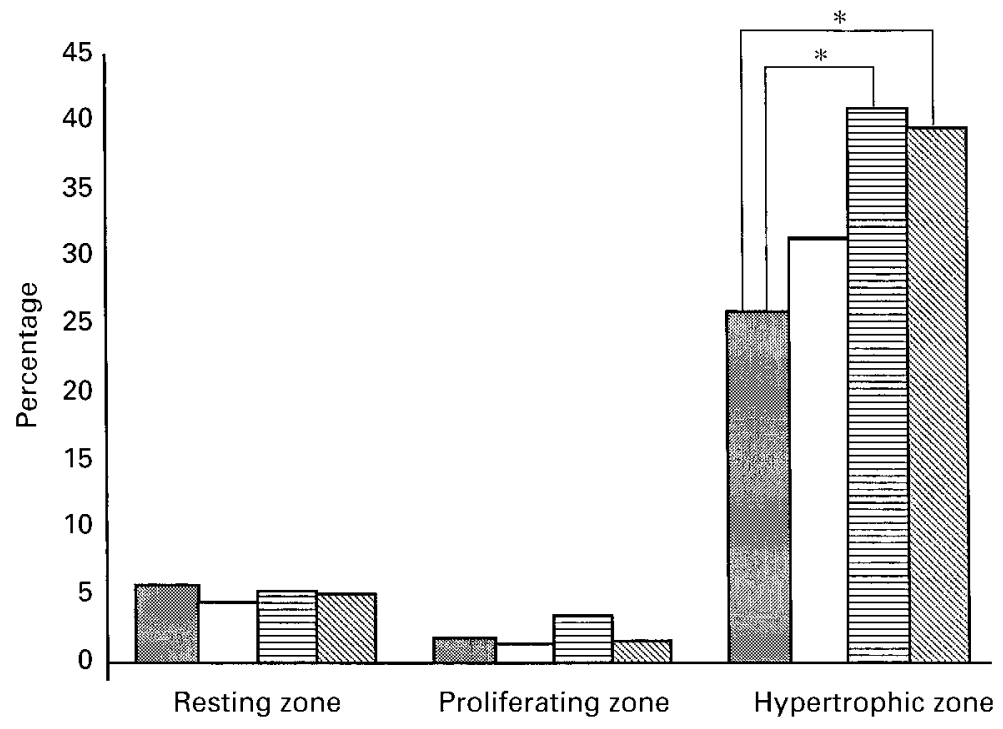

Fig. 3c

The percentage of Fas-positive, osteonectin-positive and osteocalcin-positive chondrocytes in the three zones of the growth plate in 5- to 20 -week-old rabbits. Figure $3 \mathrm{a}-$ In the resting zone, the percentage of Fas-positive cells of the 20 -week age group is significantly higher than that of the 5 -week age group. In the hypertrophic zone, the 15- and 20 -week age groups show significantly higher percentages than the 5- and 10-week age groups. Figure $3 b-$ The hypertrophic zone shows the highest percentage of osteonectin-positive cells but there is no significant difference among the groups. Figure $3 c-$ In the hypertrophic zone the percentage of osteocalcin-positive cells shows little change among the groups. Only the 5-week age group has a significantly lower percentage than the 15- and 20-week age groups $(*, p<0.05)$. 


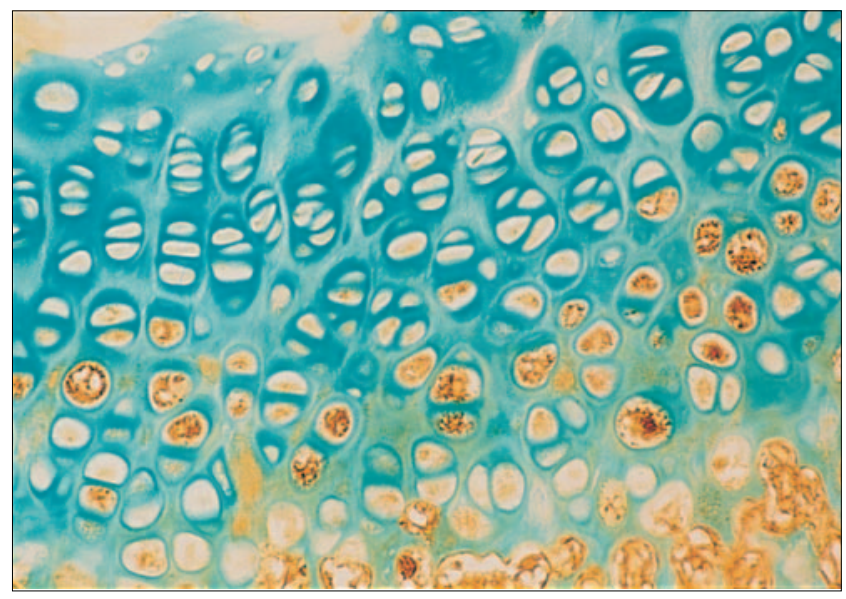

Fig. 4a

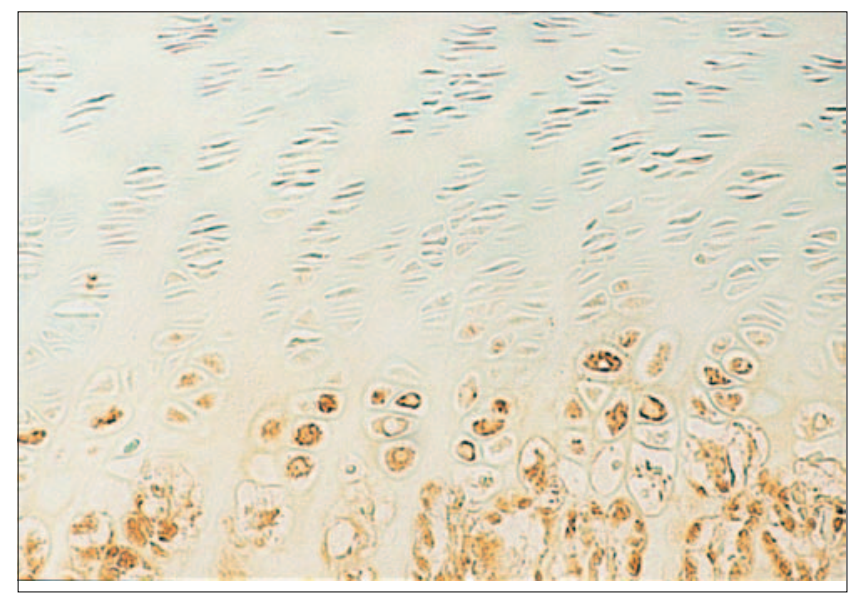

Fig. 4b

Immunostaining for osteonectin at 20 weeks (a) and osteocalcin at 10 weeks (b). In both, the cytoplasmic brown stain is clearly evident in the hypertrophic chondrocytes $(\times 160)$.

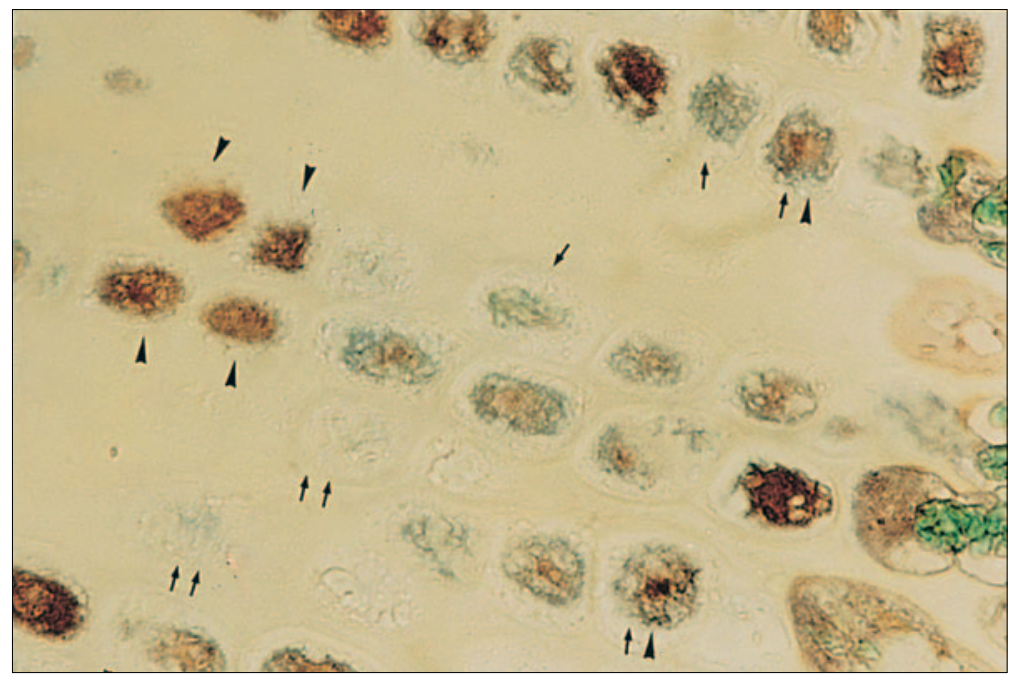

Fig. 5

Double immunostaining for Fas and osteocalcin at five weeks. The vascular front is at the bottom. Osteocalcinpositive cells are brown and the Fas receptor protein pale blue. Some chondrocytes are positive for Fas only (arrows) and others for osteocalcin only (arrowheads). There are also cells with no staining (double arrows) or simultaneous staining for both proteins (arrows and arrowhead, $\times 530$ ).

weeks from around $15 \%$ to over $40 \%$ (Fig. 3a). The positively stained cells were not evenly distributed across the length of the growth plate. Some regions had very little staining whereas in others over $50 \%$ of all hypertrophic cells stained positively.

Chondrocytes staining positively for osteonectin and osteocalcin were present in all of the growth plates (Figs 4a and $4 \mathrm{~b}$ ). The positive chondrocytes stained as strongly as osteoblasts for both antibodies. The overall percentage of positively stained cells tended to increase with age (Table I). Within the hypertrophic zone, where most of the osteonectin-positive and osteocalcin-positive cells were found (Figs $3 \mathrm{~b}$ and $3 \mathrm{c}, 4 \mathrm{a}$ and $4 \mathrm{~b}$ ), there was very little change with age. Only the five-week age group showed a significantly lower percentage of osteocalcin-positive cells than the 15- and 20-week age groups. This was in marked contrast to the doubling of the percentage of Fas-positive cells in the 15- and 20-week age groups compared with the 5- and 10-week age groups.
Double immunostaining for the Fas receptor and osteocalcin showed that osteocalcin was present in the bone matrix, osteoblasts and osteocytes as expected, but in the hypertrophic zone, staining was not uniform. Some hypertrophic chondrocytes stained for Fas alone and others for osteocalcin alone. A few chondrocytes stained for both antibodies while some were negative for both stains (Fig. 5). Generally, the strongly osteocalcin-positive cells were located in the upper hypertrophic zone although, occasionally, a terminal chondrocyte stained positively for osteocalcin alone. Many of the hypertrophic chondrocytes which did not stain for osteocalcin, stained positive for Fas, but numerous others remained unstained.

The combined staining for Fas and TUNEL also showed heterogeneity of staining. The best examples of combined staining were found in the growth plate of the 20-week-old rabbits in which many of the Fas-positive chondrocytes also had a nucleus which contained DNA breaks, as indicated by a positive TUNEL reaction product (Fig. 6). Other 


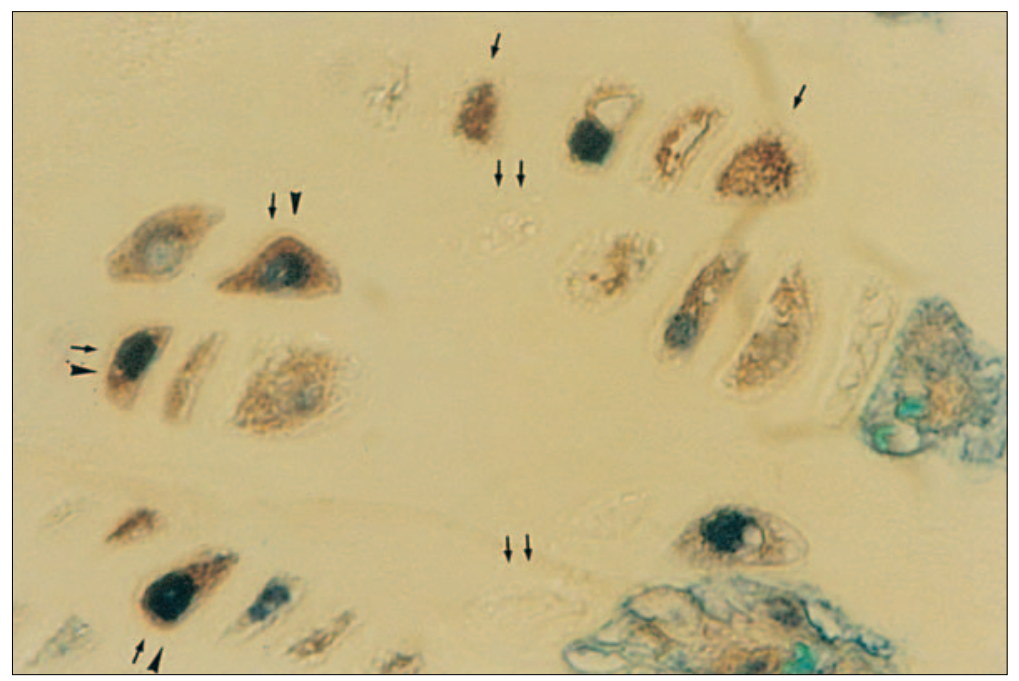

Fig. 6

Combined staining for Fas and TUNEL at 20 weeks. Fas immunostaining (brown) was followed by in situ detection of DNA breaks (TUNEL, dark blue). Some chondrocytes are positive for the Fas receptor only (arrows), but many stained for both Fas and TUNEL (arrows and arrowheads). There are also unstained chondrocytes (double arrows). Some nuclei appear almost black due to the intensity of the TUNEL reaction $(\times 530)$.

chondrocytes were labelled by Fas alone and some showed neither Fas nor TUNEL staining.

\section{Discussion}

Recent technological advances, including the availability of new monoclonal antibodies and methods for the detection of DNA breaks in situ, the hallmark of apoptotic cells, have enabled us to re-examine some of the accepted tenets of the morphology and function of the chondrocytes of the growth plate. The fact that they undergo apoptosis, the highly conserved innate mechanism by which eukaryotic cells commit suicide, ${ }^{30}$ is one of the more recent findings. ${ }^{1-6}$

Apoptosis occurs in response to physiological stimuli and is believed to be triggered by signalling through cell surface-membrane proteins. ${ }^{31}$ The Fas system is known to mediate an apoptotic signal through the membrane and is central to a number of mammalian processes of cell death. ${ }^{7,9}$ In our study, the percentage of Fas-positive cells tended to increase with age. A comparison of the number of Fas-positive cells with that of TUNEL-positive cells which we reported in our previous study, ${ }^{23}$ has shown that both are closely correlated. This was true for the whole growth plate and particularly for the hypertrophic zone, which showed the highest percentage of both Fas- and TUNEL-positive cells of the three zones of the growth plate. The exact percentages of these stainings may not represent the real rates of chondrocyte death because there are many biases in the calculation of positive ratios in immunohistochemical studies. The Fas- and TUNEL stainings, however, show the same trends of change with increasing age which suggests that apoptosis in the chondrocytes of the growth plate is mediated through the Fas system. Further evidence for this was provided by the combined Fas + TUNEL staining which showed the presence of DNA breaks in the nuclei of Fas-positive chondrocytes.
The Fas-antibody which we used identifies only the Fas receptor protein which would be expressed before DNA fragmentation became apparent. In the combined Fas + TUNEL staining, several cells expressed the Fas receptor but did not contain DNA breaks as expected. Hence the presence of this protein may indicate only a 'preparedness' for cell death and not necessarily that the cell is destined to die. For apoptosis to occur would require binding of the Fas ligand to the Fas receptor, followed by intracellular conversion of the Fas-signal to the death signal. ${ }^{9}$ It is possible that this conversion had taken place in those chondrocytes in which the presence of the Fas receptor co-localised with nuclear fragmentation. We do not yet know which cells produce the Fas ligand in the growth plate. One possibility is that the ligand may diffuse through cartilage matrix from cells in the vascular system. Another is that the chondrocytes themselves produce the Fas ligand as well as the receptor, i.e., an autocrine and/or paracrine mechanism. ${ }^{32}$ If the chondrocytes of the growth-plate do commit 'suicide', the dying cell may express both the Fas ligand and the receptor.

Osteonectin is an acidic calcium-binding protein and a major structural component of the bone matrix. ${ }^{33}$ There have been several previous immunohistochemical studies on the distribution of this protein in the growth plate. ${ }^{13,34} \mathrm{~A}$ considerable amount of osteonectin is produced in the hypertrophic zone and only low levels are detectable in the resting and proliferating zones. ${ }^{33,34}$ These results were confirmed in our study which also showed that there was little change in the percentage of osteonectin-positive chondrocytes with age in the three zones.

Previous immunohistochemical studies of the mammalian growth plate have been unable to detect osteocalcin in the hypertrophic chondrocytes in vivo, ${ }^{14,17,18}$ although its mRNA expression had been determined in vitro. ${ }^{35}$ Hence the strong positive staining which we found requires some explanation. Doubts have been expressed about the specificity of some osteocalcin antibodies which recognise epit- 
opes on proteins other than osteocalcin. ${ }^{36}$ It was found that those antibodies which were directed to epitopes near the $\mathrm{N}$-terminal end of the molecule were specific for osteocalcin antigen. Since the epitope of the present monoclonal antibody was in that region, we consider our osteocalcin staining to be specific. One reason why previous immunocytochemical studies failed to demonstrate osteocalcin in chondrocytes may be related to the fact that osteocalcin production of hypertrophic chondrocytes is only one hundredth of that observed for mature osteoblasts and hence below the level of detection if the antibody is diluted too much. ${ }^{37}$ McKee et al, ${ }^{19}$ using an osteocalcin antibody at a dilution of only 1:10, showed the presence of osteocalcin in the hypertrophic zone of the chick growth plate by electron microscopy. We used a new monoclonal antibody, also at a dilution of only 1:10, which may explain the better staining.

In bone, osteonectin and osteocalcin are components of the mineralised matrix, although they are not thought to have a role during the initiation of mineralisation. ${ }^{15}$ The function of these non-collagenous proteins in cartilage is less certain. In our study, the percentage of osteonectin- and osteocalcin-positive cells in the hypertrophic zone did not show as many changes with increasing age as that of Faspositive cells.

The double immunostaining for Fas + osteocalcin raised some interesting questions. It showed a heterogeneity among the hypertrophic chondrocytes which were either stained by Fas alone, osteocalcin alone, remained unstained or, occasionally, stained for both Fas and osteocalcin. These cells may be in a metastable or transitional state. This heterogeneity of the mammalian chondrocytes of the growth plate is not generally appreciated and may correspond to a functional heterogeneity. ${ }^{38,39}$ The positive osteocalcin staining is consistent with the possibility that some chondrocytes become bone-forming cells, as has been shown for chick chondrocytes, ${ }^{40}$ although further work is needed to clarify this.

We thank Drs K. Takamatsu and Y. Matsumura and Mr K. Shoji for their assistance in this study.

No benefits in any form have been received or will be received from a commercial party related directly or indirectly to the subject of this article.

\section{References}

1. Farnum CE, Wilsman NJ. Cellular turnover at the chondro-osseous junction of growth plate cartilage: analysis by serial sections at the light microscopical level. J Orthop Res 1989;7:654-66.

2. Lewinson D, Silbermann M. Chondroclasts and endothelial cells collaborate in the process of cartilage resorption. Anat Rec 1992; 233:504-14.

3. Gibson GJ, Kohler WJ, Schaffler MB. Chondrocyte apoptosis in endochondral ossification of chick sterna. Dev Dyn 1995;203: 468-76.

4. Hatori M, Klatte KJ, Teixeira CC, Shapiro IM. End labeling studies of fragmented DNA in the avian growth plate: evidence of apoptosis in terminally differentiated chondrocytes. J Bone Miner Res 1995; 10:1960-8

5. Bronckers AL, Goei W, Luo G, et al. DNA fragmentation during bone formation in neonatal rodents assessed by transferase-mediated end labeling. J Bone Miner Res 1996;11:1281-91.
6. Zenmyo M, Komiya S, Kawabata R, et al. Morphological and biochemical evidence for apoptosis in the terminal hypertrophic chondrocytes of the growth plate. J Pathol 1996;180:430-3.

7. Yonehara S, Ishii A, Yonehara M. A cell-killing monoclonal antibody (Anti-Fas) to a cell surface antigen co-downregulated with the receptor of tumor necrosis factor. J Exp Med 1989;169:1747-56.

8. Nagata S. Apoptosis: telling cells their time is up. Curr Biol 1996; 6:1241-3.

9. Stanger BZ. Looking beneath the surface: the cell death pathway of Fas/APO-1 (CD95). Mol Med 1996;2:7-20.

10. Yonehara S, Nishimura Y, Kishil S, et al. Involvement of apoptosis antigen Fas in clonal deletion of human thymocytes. Int Immunol 1994;6:1849-56.

11. Tanaka M, Nagata S. Fas ligand-Fas system-its function and physiological role. Exp Med 1995;13:51-5.

12. Ogasawara J, Watanabe-Fukunaga R, Adachi M, et al. Lethal effect of the anti-Fas antibody in mice. Nature 1993;364:806-9.

13. Bianco P, Silvestrini G, Termine JD, Bonucci E. Immunohistochemical localization of osteonectin in developing human and calf bone using monoclonal antibodies. Calcif Tissue Int 1988;43:155-61.

14. Boivin G, Morel G, Lian JB, et al. Localization of endogenous osteocalcin in neonatal rat bone and its absence in articular cartilage: effect of warfarin treatment. Virch Arch A Pathol Anat Histopathol 1990;417:505-12.

15. Roach HI. Why does bone matrix contain non-collagenous proteins? The possible roles of osteocalcin, osteonectin, osteopontin and bone sialoprotein in bone mineralisation and resorption. Cell Biol Int 1994;18:617-28.

16. Lian JB, Gundberg CM. Osteocalcin: biochemical considerations and clinical applications. Clin Orthop 1988;226:267-91.

17. Groot CG, Danes JK, Blok J, Hoogendijk A, Hauschka PV. Light and electron microscopic demonstration of osteocalcin antigenicity in embryonic and adult rat bone. Bone 1986;7:379-85.

18. Ohta T, Mori M, Ogawa K, Matsuyama T, Ishii S. Immunocytochemical localization of BGP in human bones in various developmental stages and pathological conditions. Virch Arch A Pathol Anat Histopathol 1989;415:459-66.

19. McKee MD, Glimcher MJ, Nanci A. High-resolution immunolocalization of osteopontin and osteocalcin in bone and cartilage during endochondral ossification in the chicken tibia. Anat Rec 1992;234: 479-92.

20. Stafford HJ, Roberts MT, Oni OO, Hay J, Gregg P. Localisation of bone-forming cells during fracture healing by osteocalcin immunocytochemistry: an experimental study of the rabbit tibia. J Orthop Res 1994;12:29-39.

21. Hughes SS, Hicks DG, O'Keefe RJ, et al. Shared phenotypic expression of osteoblasts and chondrocytes in fracture callus. $J$ Bone Miner Res 1995;10:533-44.

22. Gerstenfeld LC, Shapiro FD. Expression of bone-specific genes by hypertrophic chondrocytes: implication of the complex functions of the hypertrophic chondrocyte during endochondral bone development. J Cell Biochem 1996;62:1-9.

23. Aizawa T, Kokubun S, Tanaka Y. Apoptosis and proliferation of growth plate chondrocytes in rabbits. J Bone Joint Surg [Br] 1997; 79-B:483-6.

24. Koyama N, Ohara K, Yokota $\mathbf{H}$, et al. A one step sandwich enzyme immunoassay for $\gamma$-carboxylated osteocalcin using monoclonal antibodies. J Immunol Methods 1991;139:17-23.

25. Ueda T, Aozasa K, Tsujimoto M, et al. Prognostic significance of Ki67 reactivity in soft tissue sarcomas. Cancer 1989;63:1607-11.

26. Cordell JL, Falini B, Erber WN, et al. Immunoenzymatic labeling of monoclonal antibodies using immune complexes of alkaline phosphatase and monoclonal anti-alkaline phosphatase (APAAP complexes). J Histochem Cytochem 1984;32:219-29.

27. Brighton CT. Structure and function of the growth plate. Clin Orthop 1978;136:22-32.

28. Hunziker EB, Schenk RK, Cruz-Orive LM. Quantitation of chondrocyte performance in growth-plate cartilage during longitudinal bone growth. J Bone Joint Surg [Am] 1987;69-A:162-73.

29. Robertson WW Jr. Newest knowledge of the growth plate. Clin Orthop 1990;253:270-8. 
30. Evan GI, Brown L, Whyte M, Harrington E. Apoptosis and the cell cycle. Curr Opin Cell Biol 1995;7:825-34.

31. Hiraishi K, Suzuki K, Hakomori S, Adachi M. Le ${ }^{\gamma}$ antigen expression is correlated with apoptosis (programmed cell death). Glycobiology 1993;3:381-90.

32. Sporn MB, Todaro GJ. Autocrine secretion and malignant transformation of cells. N Engl J Med 1980;303:878-80.

33. Pacifici M, Oshima O, Fisher LW, et al. Changes in osteonectin distribution and levels are associated with mineralization of the chicken tibial growth cartilage. Calcif Tissue Int 1990;47:51-61.

34. Pacifici M, Golden EB, Oshima O, et al. Hypertrophic chondrocytes: the terminal stage of differentiation in the chondrogenic cell lineage? Ann NY Acad Sci 1990;599:45-57.

35. Strauss PG, Closs EI, Schmidt J, Erfle V. Gene expression during osteogenic differentiation in mandibular condyles in vitro. J Cell Biol 1990;110:1369-78
36. Bradbeer JN, Virdi AS, Serre CM, et al. A number of osteocalcin antisera recognize epitopes on proteins other than osteocalcin in cultured skin fibroblasts: implications for the identification of cells of the osteoblastic lineage in vitro. J Bone Miner Res 1994;9:1221-8.

37. Lian JB, McKee MD, Todd AM, Gerstenfeld LC. Induction of bonerelated proteins, osteocalcin and osteopontin, and their matrix ultrastructural localization with development of chondrocyte hypertrophy in vitro. J Cell Biochem 1993;52:206-19.

38. Simon MR, Cooke PS. Cellular heterogeneity and insulin-like growth factor I immunoreactivity among epiphysial growth plate chondrocytes in the pig. Acta Anat Basel 1988;133:66-9.

39. Silbermann M, Frommer J. Heterogeneity among chondrocytes of the mandibular condyle in foetal and postnatal mice. Arch Oral Biol 1973; 18:1549-54.

40. Roach HI, Erenpreisa J, Aigner T. Osteogenic differentiation of hypertrophic chondrocytes involves asymmetric cell divisions and apoptosis. J Cell Biol 1995;131:483-94. 